\title{
IMPLEMENTASI ACCESSIBLE TOURISM DI TMII JAKARTA
}

\author{
Nurul Sukma Lestari ${ }^{1}$, Rachel Dyah Wiastuti ${ }^{2}$, Ika Triana ${ }^{3}$ \\ 1nurul.lestari@binus.edu \\ ${ }^{1,2}$ Hotel Management Department, Faculty of Economics and Communications \\ ${ }^{3}$ Management Department, BINUS Business School Undergraduate Program \\ Bina Nusantara University. Jakarta 11480. Indonesia
}

\begin{abstract}
Indonesia is a big country consisting of various tribes and has different cultures from one to another. From this came the idea to create a tourist site with a cultural background. Taman Mini Indonesia Indah is a tourist attraction established since 1975, an attraction with the theme of Indonesian culture. Taman Mini Indonesia Indah is still a tourist destination that has been chosen by many families. Likewise, schools that still do a lot of tourist visits for study tours Visitors to Taman Mini Indonesia Indah are still the second most in Jakarta. With the development of tourism, the concept of tourism for all it becomes an absolute necessity. Because throughout the world there is also a very significant increase in the number of tourists, and ten percent have special needs including elderly people, tourists with small children, pregnant women, tourists with permanent and temporary disabilities. Therefore, the purpose of this study is to find out to what extent Taman Mini Indonesia Indah has implemented accessibility in tourism in accordance with standards set by the UNWTO. The method used is descriptive qualitative, where data is obtained through field research, documentation, checklists and literature studies. The results of the study are found that vertical movements still need to be improved because visitors using a wheelchair cannot enjoy all the regional platforms. And the suggestion from the research is to continue to improve the facilities so that everyone can access them by adding braille letters to the brochure and adding audio announcements to every tourist attraction.
\end{abstract}

\begin{abstract}
Abstrak: Indonesia merupakan negara yang sangat luas terdiri dari berbagai macam suku dan memiliki adat istiadat yang berbeda satu dengan yang lainnya. Dari sinilah munculnya ide untuk pembuatan suatu tempat wisata yang berlatar belakang budaya. Taman Mini Indonesia Indah merupakan objek wisata yang sudah lama berdiri sejak tahun 1975, suatu objek wisata yang bertemakan adat dan budaya tradisional Indonesia. Taman mini Indonesia Indah masih menjadi tujuan wisata yang banyak dipilih oleh keluarga. Demikian juga dengan sekolah-sekolah yang masih banyak melakukan kunjungan wisata ke TMII untuk study tour. Sampai saat ini pengunjung Taman Mini Indonesia Indah masih terbanyak kedua di DKI Jakarta. Dengan semakin berkembangnya dunia Pariwisata, maka saat ini Pariwisata yang dapat diakses oleh semua orang menjadi suatu keharusan yang mutlak. Karena di seluruh dunia pun terdapat peningkatan jumlah wisatawan yang sangat signifikan, dan sepuluh persennya memiliki kebutuhan khusus termasuk diantaranya adalah orang lanjut usia, wisatawan yang Bersama anak kecil, ibu hamil, wisatawan dengan disabilitas tetap dan sementara. Karena itu tujuan dari penelitian ini adalah ingin mengetahui sejauhmana Taman Mini Indonesia Indah sudah mengimplementasikan aksesibilitas yang sesuai dengan standar yang sudah ditetapkan oleh UNWTO. Adapun metode yang dipergunakan adalah deskriptif kualitatif, dimana data didapatkan melalui observasi lapangan, dokumentasi, checklist dan studi pustaka. Hasil dari penelitian adalah didapatkan bahwa pergerakan vertikal masih sangat perlu untuk ditingkatkan terutama untuk anjungan daerah, karena pengunjung yang menggunakan kursi roda tidak dapat menikmati anjungan daerah yang ada dikarenakan anjungan daerah hanya dilengkapi dengan tangga kayu ataupun batu. Dan saran dari penelitian adalah untuk terus meningkatkan fasilitas yang dapat diakses oleh semua orang dan juga adanya penambahan huruf braille ataupun bahasa isyarat serta adanya penambahan audio announcement pada setiap objek wisata yang ada.
\end{abstract}

Keywords: accessibility, disable tourist, tmii. 


\section{PENDAHULUAN}

Indonesia merupakan negara yang memiliki banyak sekali budaya dan adat istiadat yang berasal dari berbagai suku yang berbeda-beda (Setianda \& Andadari, 2015). Selain itu Indonesia memiliki alam yang sangat indah, yang menjadi daya tarik bagi wisatawan untuk datang berkunjung ke Indonesia (Sugianto, et al., 2018).

Menurut badan WTTC (World Travel \& Tourism Council) Pariwisata di Indonesia pada tahun 2016 berkontribusi sebanyak 56 milyar Dollar Amerika terhadap pendapatan kotor dalam negeri (World Travel \& Tourism Council, 2017). Pada tahun 2018 sektor Pariwisata menyumbang sebanyal 10,4\% pendapatan dunia dan mendukung 319 juta pekerjaan atau $10 \%$ dari seluruh total pekerjaan sedunia (World Travel \& Tourism Council, 2019). Berdasarkan proyeksi yang dilakukan oleh Kementrian Pariwisata pada tahun 2017 dimana dinyatakan bahwa pada tahun 2020 pariwisata akan menjadi penyumbang devisa terbesar bagi pertumbuhan Indonesia, maka dari itu pada tahun 2018 Presiden Jokowi menetapkan Pariwisata sebagai salah satu dari "The Leading Sector, selain dari sektor pertanian dan perikanan (Thaib, 2018).

Menurut UNWTO lebih dari satu milyar orang melakukan perjalanan setiap tahunnya di seluruh dunia, dimana sebagian besar terdiri dari keluarga dengan anak kecil dan atau orang tua, penyandang disabilitas atau yang memiliki kebutuhan khusus (UNWTO, 2016). UNWTO berusaha meyakinkan semua sektor pariwisata bahwa aksesibilitas untuk semua ke fasilitas, produk, dan layanan wisata harus menjadi bagian sentral dari kebijakan wisata yang bertanggung jawab dan berkelanjutan (UNWTO, n.d.). Karena pariwisata yang dapat diakses atau dapat dikatakan Pariwisata untuk semua memiliki manfaat tidak hanya bagi penyandang cacat dan berkebutuhan khusus, tetapi bagi semua orang, karena melibatkan peluang ekonomi yang besar untuk berbagai sektor diluar sektor perjalanan dan Pariwisata (UNWTO, 2014)

Dan untuk setiap wisatawan mereka ingin mendapatkan pengalaman unik yang sesuai dengan kebutuhannya (UNWTO, 2016). Bagi wisatawan yang memiliki kebutuhan khusus, perjalanan wisata dapat menjadi suatu tantangan tersendiri jika objek wisata tidak memiliki aksesibilitas yang cocok dengan kebutuhannya (Zsarnoczky, 2017). Wisatawan berkebutuhan khusus diantaranya adalah ibu yang sedang hamil, keluarga yang membawa anak kecil, orang yang sudah lanjut usia, dan orang penyandang disabilitas baik permanen maupun sementara (Simanjuntak, et al., 2018). Accessible tourism adalah pariwisata dan perjalanan yang dapat diakses oleh semua orang, cacat atau tidak, termasuk mereka yang memiliki mobilitas, pendengaran, penglihatan, kognitif, atau cacat intelektual dan psikososial, orang tua dan mereka yang cacat sementara (ENAT, 2009).

Karenanya Pariwisata di Indonesia harus sejalan dengan tema dari United Nation World Tourism Organization yaitu mengusung tema "Tourism for All" (Pariwisata untuk semua). Dapat dikatakan pariwisata untuk semua jika tersedianya aksesibilitas, keberlangsungan dan partisipasi yang adil untuk semua orang (Wiastuti, et al., 2018)

Pariwisata harus dapat diakses, dirasakan dan dinikmati oleh semua orang, baik orang yang sudah lanjut usia, keluarga dengan anak kecil, penyandang disabilitas ataupun berkebutuhan khusus (UNWTO, 2016). Setiap objek wisata harus memiliki aksesibilitas untuk semua wisatawan yang datang, terutama untuk wisatawan penyandang disabilitas dan berkebutuhan khusus (Simanjuntak, et al., 2018).

Pariwisata yang dapat diakses dapat menjadi suatu alat untuk aktualisasi pribadi dari penyandang disabilitas, dimana hal ini akan bermanfaat secara langsung untuk penyandang disabilitas dan masyarakat secara keseluruhan, dengan meningkatkan modal sosial yang pada gilirannya akan menjadi lebih berdaya dan aktif dalam dinamika masyarakat yang beragam (Devile \& Kastenholz, 2018).

Jika industry Pariwisata ingin menjaga dan mengembangkan kualitas, keberlangsuangan usaha dan daya saing dengan perusahaan yang lain, maka haruslah mendukung dan mengembangkan Pariwisata yang dapat diakses oleh semua orang (accessible tourism) karena hal ini memberikan manfaat untuk semua orang ( World Tourism Organization, 2013). Pariwisata yang mudah untuk diakses oleh semua orang dapat menawarkan peluang bagi organisasi dan daerah tujuan wisata untuk mendapatkan keunggulan kompetitif, yang 
harus sejalan dengan dengan pariwisata berkelanjutan (Silvia, 2013).

Objek wisata adalah suatu sumber daya yang bersifat permanen dan memperoleh seluruh atau sebagian penghasilannya dari pengunjung dan dikelola untuk tujuan utama kesenangan dan kegembiraan pengunjung ( Benckendorff, 2001). Salah satu objek wisata yang terkenal di Indonesia adalah Taman Mini Indonesia Indah. Dimana Taman Mini Indonesia Indah merupakan salah taman rekreasi terbesar yang berlatarbelakang budaya dengan luas 250 hektar (Wardijono, et al., 2017) dan pada tahun 2016 saja memiliki jumlah pengunjung sebanyak 5.371.765 orang ( Anugerah \& Sugandi, 2018). Taman Mini Indonesia Indah menempati peringkat kedua untuk tempat wisata di Jakarta dengan daya Tarik pengunjung yang tinggi ( Puspasari \& , 2018).

Konsep pariwisata yang dapat diakses mengacu pada adaptasi lingkungan dan produk serta layanan pariwisata untuk memungkinkan akses, penggunaan, dan kenikmatan oleh semua pengguna, di bawah prinsip Universal Design (UNWTO, 2016). "Desain universal" adalah suatu desain produk, lingkungan, program dan layanan yang dapat digunakan oleh semua orang, sejauh mungkin, tanpa perlu adaptasi atau desain khusus ( World Tourism Organization, 2013).

Permasalahan yang ada adalah Taman Mini Indonesia Indah merupakan salah satu objek wisata yang sudah berdiri sejak lama sehingga kemungkinan besar adalah belum menerapkan Pariwisata yang dapat diakses oleh semua orang.

Tujuan dari penelitian ini adalah untuk mengetahui sejauh mana Taman Mini Indonesia Indah sudah mengimplementasikan Accessible tourism untuk semua objek wisata yang ada di dalamnya dilihat berdasarkan standard dari UNWTO.

Adapun manfaat dari penelitian ini adalah bisa menjadi bahan masukan untuk pengelolaan Taman Mini Indonesia Indah untuk lebih menerapkan accessible tourism agar semakin banyak pengunjung yang akan mendatangi Taman Mini Indonesia Indah.

\section{METODE PENELITIAN}

Penelitian ini mengambil tempat di Taman Mini Indonesia Indah, Jakarta Timur. Objek penelitian terdiri dari Anjungan Daerah, museum, Flora \& fauna dan wahana rekreasi Taman Mini Indonesia Indah.

Metode yang digunakan adalah metode penelitian kulitatif. Penelitian kualitatif bertujuab untuk memahami pengalaman manusia dalam pendekatan humanistik, interpretative (Jackson, et al., 2007) berdasarkan pada gagasan bahwa "kenyataan" itu subyektif: Setiap manusia membangun pandangan individu, pribadi tentang dunia berdasarkan interaksi spesifiknya dengan dunia luar (termasuk orang-orang yang menjadi bagian dari dunia ini) (Cropley, 2019).

Data primer didapatkan dari observasi lapangan secara langsung dan melalui wawancara kepada beberapa sumber terkait. Observasi lapangan dilakukan selama kurun waktu selama empat bulan, dimulai sejak bulan January - April 2019 dengan menggunakan checklist sebagai petunjuk selama melakukan observasi. Data sekunder didapatkan melalui dokumentasi yang dilakukan selama observasi lapangan dan studi pustaka.

Variable yang akan diteliti dalam penelitian ini adalah aksesibilitas pada objek wisata yang ada di dalam Taman Mini Indonesia Indah. Menurut ( World Tourism Organization, 2013) ada tujuh persyaratan umum aksesibilitas yang harus dipenuhi, yaitu:

1)Area parkir; harus ada ruang parkir khusus dengan identifikasi yang tepat untuk kendaraan orang dengan mobilitas terbatas, sedekat mungkin ke titik masuk dan keluar. Dan tersedia dalam ukuran yang memadai untuk keleluasaan pengunjung yang menggunakan kuris roda, adanya petugas yang berjaga dan adanya kamera pengawas; 2) Komunikasi; Penggunaan bahasa isyarat dan huruf braille, sarana dan mode komunikasi dan semua cara lain harus diterima dan difasilitasi. Telepon dan sistem komunikasi dan yang lainnya harus dirancang, dibuat dan tersedia untuk penggunaan sehingga mereka dapat digunakan oleh semua orang tanpa memandang tinggi badan, mobilitas, atau masalah sensoriknya; 3) Signage; konter informasi harus di beri tanda dan memiliki area yang dapat diakses yang disediakan untuk digunakan oleh orang-orang dengan mobilitas terbatas yang terletak sedekat mungkin ke pintu masuk. Pengumuman harus berupa visual dan dapat didengar. Alarm kebakaran 
harus memancarkan sinyal visual dan akustik. Penandaan pintu darurat harus jelas dan menyala dengan baik. Fasilitas harus memiliki peta yang menunjukkan titik pertemuan dan prosedur evakuasi; 4) Pergerakan Horisontal; Langkah-langkah yang efektif harus diambil untuk memastikan bahwa para penyandang cacat dapat berpindah tempat sendiri secara maksimal. Koridor harus bebas dari hambatan fisik dan visual dan memiliki lebar untuk memungkinkan lewatnya dua kursi roda secara berdampingan dan tidak menghalangi sirkulasi, atau menyediakan titik untuk saling melewati; 5) Pergerakan Vertikal; terdiri dari tangga, lift dan jalan yang landai. Untuk bangunan bertingkat harus memiliki beberapa lift dengan ukuran yang cukup luas bagi dua buah kursi roda untuk masuk dan keluar. Lift harus di desain khusus dan dilengkapi dengan fasilitas untuk pengunjung dengan keterbatasan penglihatan. Lift juga harus dilengkapi dengan sistem darurat untuk pengunjung dengan keterbatasan pendengaran. 6) Fasilitas kebersihan umum; tersedia toilet dan wastafel untuk penyandang disabilitas yang terletak satu area dengan toilet yang lain. 7)Harga; tidak ada penambahan harga untuk fasilitas-fasilitas khusus untuk pengunjung berkebutuhan khusus.

Adapun yang menjadi objek di dalam penelitian ini adalah semua objek wisata yang ada di dalam Kawasan Taman Mini Indonesia Indah. Dimana peneliti akan jabarkan dalam bentuk tabel berikut dengan singkatannya agar lebih mudah untuk dipahami.

Tabel 1. Objek Penelitian

\begin{tabular}{ccc}
\hline No. & Nama & Singkatan \\
\hline 1. & Anjungan Daerah & AD \\
\hline 2. & Museum & MS \\
\hline 3. & Flora dan Fauna & FF \\
\hline 4. & Wahana Rekreasi & WR \\
\hline Sumber Hasil Penelitian, 2019 &
\end{tabular}

HASIL DAN PEMBAHASAN

Hasil

Area Parkir

Terdapat tiga puluh tiga Anjungan Daerah yang letaknya tersebar di seluruh area Taman Mini Indonesia Indah. Ada beberapa museum yang tidak memiliki area parkir, sehingga untuk pengunjung yang datang mempergunakan area parkir umum yang memang disediakan oleh Taman Mini
Indonesia Indah. Area parkir umum dapat berupa sebuah lapangan, trotoar jalan ataupun di bahu-bahu jalan. Kalaupun Anjungan Daerah memiliki area parking, tidak ada area parkir yang dikhususkan untuk penyandang disabilitas. Area parkir dari Anjungan terletak di bagian depan sedangkan area parkir umum tersedia di bagian depan dan belakang anjungan. Tidak ada yang mengawasi area parkir. Untuk area parkir umum tersedia cukup luas, sehingga kendaraan besar seperti bus sampai kendaraan kecil seperti motor dapat diparkir disana, sedangkan untuk area parkir yang berada di area anjungan biasanya hanya tersedia untuk mobil ataupun motor, tidak dapat menampung bus, sehingga tetap saja bus harus memarkirnya di area parkir umum.

Terdapat delapan belas museum di seluruh area Taman Mini Indonesia Indah. Sama dengan anjungan daerah, tidak semua museum memiliki area parkir, dan jika adapun tidak terdapat area parkir yang dikhususkan untuk area parkir penyandang disabilitas. Area parkir yang paling menyulitkan untuk pengunjung adalah museum Hakka dikarenakan letaknya yang sangat jauh dari pintu masuk museum dan keadaan jalan yang menghubungkan area parkir dengan pintu masuk museum masih berbatu-batu sehingga akan menyulitkan untuk pengunjung yang menggunakan kursi roda dan yang membawa kereta bayi. Jarak dari area parkir dengan pintu masuk museum sekitar 500 meter, hal ini disebabkan karena museum Hakka masih dalam tahap pembangunan untuk area sekitar museum. Selain dari museum Hakka, area parkir yang letaknya agak jauh dari pintu masuk museum adalah museum transportasi dan museum listrik dan energi baru. Jalanan yang menghubungkan area parkir dengan museum sudah rata (beraspal), sehingga masih bisa dijalanin oleh kursi roda maupun kereta bayi.

Ada sembilan kawasan yang termasuk di dalam kategori flora \& fauna, dan hanya taman prasasti APEC yang tidak memiliki area parkir, dikarenakan letaknya yang berada di tengah persimpangan jalan antara gedung pusat pengelola dan Museum Indonesia. Taman Prasati APEC hanya bisa dihampiri dengan berjalan kaki. Sedangkan untuk kawasan flora \& fauna yang lain area parkir tersedia di bagian depan museum, tetapi tidak tersedia area parkir khusus untuk penyandang disabilitas. Taman bekisar, Taman kaktus, 
Taman apotik hidup dan Taman melati mengunakan bahu jalan sebagai area parkir.

Untuk wahana rekreasi ada sembilan kawasan yang termasuk di dalamnya. Snowbay waterpark, teater 4 dimensi, tithan samirono dan taman legenda keong mas merupakan wahana rekreasi yang memiliki area parkir paling dekat dengan pintu masuk. Sedangkan untuk wahana yang memiliki area parkir paling jauh dari pintu masuk adalah teater Imax Keong Mas, dengan jalan penghubung dari area parkir ke pintu masuk sudah beraspal sehingga akan memudahkan bagi pengguna kursi roda dan pengunjung yang membawa kereta bayi.

Untuk keseluruhan area parkir yang berada di tiap objek wisata tidak memiliki petugas yang berjaga di tempat dan tidak terdapat kamera pengawas.

Untuk hasil pengamatan pada variabel area parkir secara menyeluruh dapat dilihat pada tabel dibawah ini.

Tabel 2. Area Parkir

\begin{tabular}{|c|c|c|c|c|c|}
\hline No. & Indikator & $\mathrm{AD}$ & MS & $\mathrm{FF}$ & WR \\
\hline 1. & $\begin{array}{l}\text { Area } \\
\text { parkir } \\
\text { khusus } \\
\text { disabilitas }\end{array}$ & $\mathrm{X}$ & $\mathrm{X}$ & $\mathrm{X}$ & $\mathrm{X}$ \\
\hline 2. & $\begin{array}{l}\text { Dekat } \\
\text { dengan } \\
\text { pintu } \\
\text { masuk } \\
\text { dan } \\
\text { keluar }\end{array}$ & $\mathrm{V}$ & $\mathrm{X}$ & $\mathrm{V}$ & $\mathrm{X}$ \\
\hline 3. & $\begin{array}{l}\text { Ukuran } \\
\text { yang } \\
\text { memadai } \\
\text { untuk } \\
\text { kursi roda }\end{array}$ & $\mathrm{V}$ & $\mathrm{V}$ & $\mathrm{V}$ & V \\
\hline 4. & $\begin{array}{l}\text { Adanya } \\
\text { petugas } \\
\text { dan } \\
\text { kamera } \\
\text { pengawas }\end{array}$ & $\mathrm{X}$ & $\mathrm{X}$ & $\mathrm{X}$ & $\mathrm{X}$ \\
\hline
\end{tabular}

Sumber: Hasil Penelitian, 2019

\section{Komunikasi}

Pusat Informasi Taman Mini Indonesia Indah memiliki peta yang diberi nama"Keliling Indonesia dalam 1 Hari". Isi peta ini cukup lengkap dengan adanya peta kese;uruhan dari Taman Mini Indonesia Indah ditambah dengan adanya harga untuk semua tiket masuk objek wisata yang berbayar, keterangan waktu buka dan tutup, serta informasi untuk reservasi berikut nomor telepon yang dapat dihubungi. Tetapi sangat disayangkan peta ini hanya tersedia dalam bahasa Indonesia. Adalagi brosur yang disediakan oleh pusat informasi yang merupakan acara per dua bulanan yang diselenggarakan oleh Taman Mini Indonesia Indah, brosur ini tersedia dalam dua bahasa, yaitu Indonesia dan Inggris. Kemudian ada juga tersedia digital dokumen yang dapat diunduh melalui web resmi, yang berisikan acara yang akan dilaksanakan di Taman Mini Indonesia Indah. Digital dokumen ini diterbitkan dua bulan sekali. Untuk semua objek wisata yang ada di Taman Mini Indonesia Indah tidak tersedia alat komunikasi yang menggunakan huruf braille maupun bahasa isyarat.

Selain pusat informasi beberapa dari anjungan daerah seperti, anjungan DKI Jakarta, Bangka Belitung, Kalimantan Selatan, dan Kepulauan Riau menyediakan brosur yang dibagikan untuk pengunjung yang datang ke anjungan., khusus untuk anjungan DKI Jakarta menyediakan brosur dalam bahasa Indonesia, Inggris dan Mandarin. Untuk Audio visual tidak terdapat di anjungan manapun. Anjungan Dki Jakarta dan Sumatera Barat sebetulnya memiliki audio visual terminal hanya saja keduanya dalam keadaan rusak. Untuk audio berupa speaker terletak di bagian luar dari anjungan, tetapi tidak dapat dipastikan bahwa keseluruhannya dapat berfungsi dengan baik pada saat dipergunakan.

Untuk museum, lebih banyak yang dilengkapi dengan terminal yang menyajikan audio visual. Bahkan untuk museum olahraga dilengkapi dengan suatu aplikasi yang bernama SIJI, yaitu suatu aplikasi terbaru yang dapat menampilkan video tiga dimensi. Selain itu audio visual yang berada di area museum menampilkan informasi terkait dari museum tersebut. Ada juga beberapa museum seperti museum pusaka, museum listrik dan energy baru, museum asmat, pusat peragaan IPTEK, museum Indonesia, museum Perangko dan Museum Hakka yang menyediakan juga brosur. Hanya saja brosur-brosur tersebut tersedia dalam bahasa Indonesia, kecuali untuk museum Hakka yang menyediakan brosur dalam tiga bahasa, yaitu Indonesia, Inggris dan Mandarin. 
Untuk kawasan flora \& fauna tidak tersedia brosur tetapi beberapa menyediakan audio visual atau hanya alat komunikasi secara visual saja. Dunia air tawar merupakan satusatunya yang memiliki audio visual berupa film tiga dimensi tetapi ini merupakan film berbayar. Sedangkan untuk taman burung, taman bekisar dan taman apotik hidup memiliki visual konten yang sebagian besar tersedia dalam bahasa Indonesia, dan sebagian kecil menggunakan bahasa Inggris.

Untuk wahana rekreasi yang menyediakan brosur adalah Teater Imax Keong Mas, Taman Legenda Keong Mas, dan Skyworld tetapi hanya tersedia dalam bahasa Indonesia. Tersedia audio visual berbayar yang terdapat di teater Imax keong mas dan Skyworld. Audio Visual yang terdapat berupa film yang bermuatan pendidikan. Ada juga film yang berbahasa Inggris.

Untuk hasil pengamatan pada variabel komunikasi secara menyeluruh dapat dilihat pada tabel dibawah ini:

Tabel 3. Komunikasi

\begin{tabular}{cccccc}
\hline No. & Indikator & AD & MS & FF & WR \\
\hline 1. & Memiliki & V & V & V & V \\
sarana & & & & \\
komunikasi & & & & \\
(brosur, & & & & \\
digital & & & & \\
dokumen, & & & & \\
standing & & & & \\
banner, & & & & \\
spanduk, & & & & \\
dll) & & & & \\
\hline Sarana & $\mathrm{V}$ & $\mathrm{V}$ & $\mathrm{V}$ & $\mathrm{V}$ \\
komunikasi & & & & \\
minimal & & & & \\
terdiri dari 2 \\
bahasa, \\
yaitu \\
Indonesia \\
dan Inggris
\end{tabular}

Sumber: Hasil Penelitian, 2019

\section{Signage}

Untuk konter tiket masuk ke Taman Mini Indonesia Indah terletak di pintu masuk dibedakan untuk pintu masuk kendaraan bermotor dan pintu masuk untuk pengunjung yang berjalan kaki. Terdapat keterangan mengenai harga dan jam buka serta tutup dari Taman Mini secara umum.

Untuk museum-museum yang ada di Taman Mini Indonesia Indah semuanya memiliki konter informasi yang letaknya di area depan museum. Ada yang letaknya terpisah dengan loket penjualan karcis masuk ada yang menjadi satu, dan ada tanda yang merupakan pemberitahuan tentang konter atau loket pembelian tiket masuk. Ada tanda yang tersedia dalam tulisan dan ada juga yang menggunakan gambar atau bahkan menggunakan keduanya, yaitu gambar dan tulisan. Tanda-tanda terletak di tempat yang mudah untuk terlihat, terutama tanda untuk menunjukan pintu keluar darurat. Tersedia speaker untuk pemberitahuan jika terjadi keadaan darurat. Ada juga beberapa tanda yang terletak di lantai, menyerupai jejak kaki, yang dimaksudkan agar pengunjung dapat mengikuti ke arah yang dituju. Tanda yang berupa tulisan tersedia dalam bahasa Inggris dan Indonesia.

Anjungan Daerah tidak semua memiliki konter informasi, kalaupun ada meja informasi sebagian besar tidak ada petugas yang bertugas, beberapa anjungan hanya meninggalkan buku tamu untuk para pengunjung mengisi data kedatangannya. Hal ini mungkin disebabkan karena untuk masuk ke dalam anjungan daerah tidak memerlukan tiket/bebas biaya. Tetapi beberapa anjungan daerah yang memiliki meja informasi berikut petugas yang bertugas di belakang mejanya adalah adalah, anjungan Sumatera Barat dan anjungan DKI Jakarta. Untuk anjungan Sumatera Barat, meja informasi ini adalah tempat dimana pegunjung mengisi buku tamu dan jika pengunjung ingin menyewa baju adat untuk melakukan pemotretan di dalam rumah Gadang. Untuk tanda yang terdapat di anjungan daerah ada yang terletak di dalam anjungan dan ada yang terletak diluar area anjungan (halaman luar). Tanda-tanda tersebut ada yang dalam bentuk tulisan, gambar atau keduanya dan tersedia dalam bahasa Inggris dan Indonesia. Tersedia alarm kebakaran di dalam tiap anjungan. 
Untuk kawsan flora \& fauna yang memiliki konter penjualan tiket adalah dunia air tawar dan serangga dan taman burung dan bekisar. Sedangkan untuk taman kawasan yang lain karena terletak di area terbuka tidak tersedia konter informasi. Tanda untuk keadaan darurat juga tidak ditemukan di Monumen KTT Non-Blok, taman Tionghoa dan Taman prasati APEC, karena ketiga kawasan betul-betul terletak di luar ruangan yang terbuka luas. Untuk flora dan fauna yang terletak di ruangan memiliki tanda yang menunjukan pintu masuk dan keluar, pintu darurat, toilet, tanda larangan, yang semuanya terletak di tempat yang mudah untuk terlihat dari manapun oleh pengunjung.

Wahana rekreasi semuanya memiliki konter untuk penjualan tiket masuk yang juga menjadi konter informasi. Tanda yang terpasang di semua wahana ini tersedia dalam bentuk gambar dan tulisan, ataupun merupakan kombinasi dari gambar dan tulisan. Terletak di tempat yang mudah untuk terlihat oleh pengunjung, terutama tanda untuk keadaan darurat letaknya benar-benar tidak terhalang oleh apapun.

Untuk hasil pengamatan pada variabel signage secara menyeluruh dapat dilihat pada tabel dibawah ini:

Tabel 4. Signage

\begin{tabular}{|c|c|c|c|c|c|}
\hline No. & Indikator & $\mathrm{AD}$ & MS & FF & WR \\
\hline 1. & $\begin{array}{c}\text { Area } \\
\text { informasi/tiket } \\
\text { luas }\end{array}$ & $\mathrm{V}$ & V & $\mathrm{V}$ & $\mathrm{V}$ \\
\hline 2. & $\begin{array}{c}\text { Informasi } \\
\text { disajikan } \\
\text { dalam visual } \\
\text { dan audio }\end{array}$ & X & V & $\mathrm{V}$ & X \\
\hline 3. & $\begin{array}{l}\text { Penggunaan } \\
\text { simbol/gambar } \\
\text { universal }\end{array}$ & $\mathrm{V}$ & $\mathrm{V}$ & $\mathrm{V}$ & $\mathrm{V}$ \\
\hline 4. & $\begin{array}{c}\text { Alarm } \\
\text { kebakaran } \\
\text { tersedia dalam } \\
\text { visual (lampu } \\
\text { merah) dan } \\
\text { audio }\end{array}$ & $\mathrm{V}$ & $\mathrm{V}$ & $\mathrm{V}$ & $\mathrm{V}$ \\
\hline 5. & $\begin{array}{c}\text { Tanda } \\
\text { emergency } \\
\text { exit jelas } \\
\text { terlihat }\end{array}$ & $\mathrm{V}$ & V & V & $\mathrm{V}$ \\
\hline
\end{tabular}

Sumber: Hasil Penelitian, 2019

\section{Pergerakan Horisontal}

Untuk area Taman Mini Indonesia Indah secara keseluruhan sangatlah luas dan pengunjung yang menggunakan kursi roda maupun pengunjung yang membawa kereta bayi dapat berkeliling area lebih mudah karena jalanan yang sudah beraspal dan tersedia trotoar yang memadai di kiri dan kanan jalan.

Anjungan daerah, memiliki area halaman yang luas sehingga akan sangat memungkinkan untuk dua buah kursi roda saling berpapasan.

Museum, pada bagian dalam museum terdapat area yang cukup luas untuk pengunjung yang menggunakan kursi roda untuk bermobilisasi, demikian juga jika harus berpapasan area masih cukup lebar.

Kawasan flora dan fauna yang tidak memiliki area yang luas adalah taman prasasti APEC yang terletak di persimpangan jalan sehingga akan sulit untuk didekati oleh pengunjung yang menggunakan kursi roda.

Wahana rekreasi memiliki area yang cukup luas untuk pengunjung dengan kursi roda dan yang membawa kereta bayi. Hanya kereta gantung yang tidak memiliki akses jalan untuk pengunjung dengan kursi roda. Karena pada saat pengunjung akan masuk ke dalam kereta gantung, kereta tetap bergerak walaupun pelan, sehingga tidak memungkinkan untuk pengunjung dengan kuris roda untuk menaiki wahana ini.

Untuk hasil pengamatan pada variabel pergerakan horisontal secara menyeluruh dapat dilihat pada tabel dibawah ini:

Tabel 5. Pergerakan Horisontal

\begin{tabular}{cccccc}
\hline No. & Indikator & AD & MS & FF & WR \\
\hline $1 . \quad \begin{array}{l}\text { Jalan masuk } \\
\text { bebas dari } \\
\text { halangan }\end{array}$ & $\mathrm{V}$ & $\mathrm{V}$ & $\mathrm{V}$ & $\mathrm{V}$ \\
\hline 2. & $\begin{array}{c}\text { Koridor lebar, } \\
\text { cukup dilalui } \\
\text { dua kursi roda }\end{array}$ & $\mathrm{V}$ & $\mathrm{V}$ & $\mathrm{V}$ & $\mathrm{V}$ \\
\hline $3 . \quad \begin{array}{c}\text { Area wisata } \\
\text { luas, kursi } \\
\text { roda leluasa } \\
\text { untuk } \\
\text { bergerak }\end{array}$ & & & & & \\
\hline & & & & & \\
\hline Sumber: Hasil Penelitian, 2019 & & \\
Pergerakan Vertikal \\
Tidak tersedia lift untuk semua anjungan
\end{tabular}

Tidak tersedia lift untuk semua anjungan daerah. Sedangkan hampir sembilan puluh 
persen anjungan daerah yang ada berupa rumah panggung yang hanya dilengkapi dengan tangga yang terbuat dari kayu ataupun batu. Adapun anjungan daerah yang tidak berupa rumah panggung tetap memiliki gap antara jalan masuk dengan area dalam anjungan, dan dilengkapi dengan anak tangga tanpa tersedia ramp, kecuali di anjungan Jawa Timur, ada beberapa area yang tersedia ramp.

Untuk museum, tidak semua museum menyediakan ramp (jalanan landai). Museum Indonesia, museum Hakka, museum Olahraga, museum Telekomunikasi, museum Pusaka, Museum serangga dan kupu-kupu serta museum Timor Timur adalah museum yang tidak memiliki ramp/jalanan landai yang berasal dari jalanan luar (area luar) menuju ke bagian dalam museum. Tetapi untuk dibagian dalam museum sebagian besar menyediakan ramp untuk pengunjung yang menggunakan kursi roda dan yang membawa kereta bayi. Sedangkan beberapa museum dilengkapi dengan lift seperti museum Indonesia, museum penerangan, museum Hakka, museum listrik dan energy baru dan museum keprajuritan. Untuk dua museum terakhir lift yang tersedia sedang dalam keadaan rusak. Lift yang tersedia di beberapa museum ukurannya sangat kecil sehingga untuk satu kursi roda saja sudah cukup susah untuk bermanuver. Dan pada lift juga tidak tersedia tombol dengan huruf braille.

Untuk kawasan flora dan fauna, taman kaktus, dan taman prasasti APEC adalah kawasan yang tidak dilengkapi dengan ramp. Taman prasasti APEC terletak di persimpangan jalan dan berbatasan dengan trotoar pejalan kaki. Sedangkan untuk taman kaktus yang memiliki kawasan tersendiri jalanan masuknya banyak menggunakan anak tangga.

Untuk wahana rekreasi, teater Imax Keong Mas merupakan wahana yang tidak dilengkapi dengan ramp. Jalan yang menghubungkan area parkir dengan pintu masuk dihubungkan dengan anak tangga yang cukup banyak. Walupun pengunjung turun di dekat pintu masuk tetap ada anak tangga yang menghubungkan dari area drop off mobil dengan pintu masuk.

Untuk hasil pengamatan pada variabel pergerakan vertikal secara menyeluruh dapat dilihat pada tabel dibawah ini:
Tabel 6. Pergerakan Vertikal

\begin{tabular}{cccccc}
\hline No. & Indikator & AD & MS & FF & WR \\
\hline 1. & Elevator & X & V & X & X \\
\hline 2. & Stair and ramp & V & V & V & V \\
\hline
\end{tabular}

Sumber: Hasil Penelitian, 2019

\section{Fasilitas Kebersihan Umum}

Toilet umum dan wastafel banyak tersebar di semua area Taman Mini Indonesia Indah, diluar yang disediakan di area-area objek wisata.

Hampir disetiap anjungan daerah tersedia toilet untuk pengunjung. Sebagian ada yang tersedia gratis ada yang harus membayar sebesar Rp. 2000,-. Dan toilet yang tersedia banyak diantaranya masih merupakan toilet jongkok. Tidak tersedia toilet untuk penyandang disabilitas. Letak toilet juga sulit untuk dijangkau oleh pengunjung disabilitas, karena letaknya yang jauh di belakang anjungan kemudian jalanan yang menghubungkannya pun kecil dan tidak terlalu rata. Ruangan toilet terlalu kecil untuk kursi roda sehingga pengunjung yang menggunakan kursi roda akan kesulitan untuk menggunakan toilet tersebut.

Toilet untuk pengunjung disabilitas hanya tersedia di Bayt Al Quran dan Museum Istiqlal. Walaupun tersedia toilet untuk disabilitas yang dilengkapi dengan pegangan dari besi pada dinding bagian dalam, posisi dari pintu toilet tetap menyulitkan karena begitu masuk harus berbelok ke kanan untuk mencapai toilet duduk yang tersedia. Luas ruang toilet untuk disabilitas tidaklah terlalu besar, tetapi masih cukup memadai untuk kursi roda berputar. Tetapi tidak ada tanda khusus disabilitas pada ruang toilet ini. Dan untuk wastafel menggunakan wastafel yang sama dengan pengunjung umum lainnya. Selain itu museum yang lain hanya menyediakan toilet umum biasa untuk semua pengunjung yang datang.

Untuk kawasan flora dan fauna, hanya dunia air tawar yang memiliki toilet khusus pengunjung, yang berada di dalam area tersebut. Sedangkan untuk kawasan yang lain tidak tersedia toilet pengunjung, tetapi masih ada toilet umum yang berada di sekitar kawasan yang bersangkutan.

Sedangkan untuk wahana rekreasi terdapat toilet untuk pengunjung, ada yang bercampur dengan toilet umum, ada yang khusus untuk pengunjung. Seperti wahana kereta gantung dan titihan samirono, karena 
letaknya berdekatan dengan toilet umum, maka wahana ini tidak menyediakan toilet khusus pengunjung. Sedangkan wahana yang lain menyediakan toilet khusus untuk pengunjung, walaupun tetap tidak tersedia toilet untuk pengunjung disabilitas.

Untuk hasil pengamatan pada variabel fasilitas kebersihan umum secara menyeluruh dapat dilihat pada tabel dibawah ini:

Tabel 7. Fasilitas Kebersihan Umum

\begin{tabular}{|c|c|c|c|c|c|}
\hline No. & Indikator & $\mathrm{AD}$ & MS & FF & WR \\
\hline 1. & $\begin{array}{l}\text { Toilet untuk } \\
\text { disabilitas }\end{array}$ & $\mathrm{X}$ & $\mathrm{X}$ & $X$ & $\mathrm{X}$ \\
\hline 2. & $\begin{array}{lr}\text { Luas } & \text { area } \\
\text { toilet } & \text { cukup } \\
\text { untuk } & \text { kursi } \\
\text { roda } & \end{array}$ & $\mathrm{X}$ & $\mathrm{X}$ & $X$ & $\mathrm{X}$ \\
\hline 3. & $\begin{array}{l}\text { Ada alat bantu } \\
\text { di dalam toilet }\end{array}$ & $\mathrm{X}$ & $\mathrm{X}$ & $\mathrm{X}$ & $\mathrm{X}$ \\
\hline 4. & $\begin{array}{c}\text { Ada wastafel } \\
\text { untuk } \\
\text { disabilitas }\end{array}$ & $\mathrm{X}$ & $\mathrm{X}$ & $\mathrm{X}$ & $\mathrm{X}$ \\
\hline
\end{tabular}

Sumber: Hasil Penelitian, 2019

\section{Harga}

Untuk keseluruhan objek wisata yang berada di Taman mini Indonesia Indah tidak ada penambahan harga untuk pengunjung yang berkebutuhan khusus, baik itu penyandang disabilitas maupun yang membawa kereta bayi. Ada juga objek wisata yang menyediakan kursi roda secara gratis untuk yang membutuhkan seperti di Museum Hakka.

Untuk hasil pengamatan pada variabel harga secara menyeluruh dapat dilihat pada tabel dibawah ini:

Tabel 8. Harga

\begin{tabular}{cccccc}
\hline No. & Indikator & AD & MS & FF & WR \\
\hline 1. & Tidak ada & V & V & V & V \\
penambahan \\
harga untuk \\
fasilitas \\
disabilitas
\end{tabular}

Sumber: Hasil Penelitian, 2019

\section{Pembahasan}

Dari keseluruhan hasil obersevasi yang dilakukan oleh peneliti jika dibandingkan dengan persyaratan aksesibilitas yang dikeluarkan oleh UNWTO, maka dapat dikatakan bahwa untuk area parkir, keseluruhan tempat parkir baik yang berada di tiap objek wisata maupun yang bersifat umum di dalam lingkungan Taman Mini Indonesia Indah belum memenuhi persyaratan aksesibilitas. Karena belum adanya area parkir yang dikhususkan untuk penyandang disabilitas dan belum adanya penjagaan dari petugas dan kamera pengawas. Area parkir di beberapa objek wisata sudah cukup besar untuk dapat menampung kendaran bermotor dari bus sampai dengan sepeda motor. Tetapi yang menjadi kendala lain adalah beberapa area parkir terletak agak jauh dari pintu masuk, dan keadaan jalanan peghubungnya kadangkala tidak terlalu baik atau belum diaspal sehingga akan menyulitkan untuk kursi roda dan kereta bayi pada saat melalui jalanan tersebut.

Berdasarkan persyaratan untuk aksesibilitas yang sudah ditetapkan dari UNWTO untuk komunikasi, Taman Mini Indonesia Indah sudah memenuhi syarat aksesibilitas. Terdapat brosur, audio visual dan digital content yang berisikan informasi mengenai peta dari area Taman Mini Indonesia Indah, harga tiket masuk untuk semua objek wisata berbayar, dan juga tersedianya informasi mengenai jam buka dan tutup. Beberapa brosur juga sudah tersedia dalam bahasa lain selain Indonesia seperti bahasa Inggris dan Mandarin.

Berdasarkan persyaratan untuk aksesibilitas yang sudah ditetapkan dari UNWTO untuk signage, sudah dipenuhi dengan cukup baik oleh Taman Mini Indonesia Indah. Tanda yang menggunakan gambar sudah memakai universal design sehingga siapapun yang melihat dapat memahami artinya. beberapa tanda masih tersedia hanya dalam bahasa Indonesia, walapun sudah banyak yang menggunakan dua bahasa, yaitu Indonesia dan Inggris. Dari segi peletakan masih harus diatur ulang terutama untuk anjungan daerah, karena kadang-kadang hanya diletakan saja di lantai sehingga lebih mudah terlewatkan oleh pengunjung.

Berdasarkan persyaratan untuk aksesibilitas yang sudah ditetapkan dari UNWTO untuk pergerakan horisontal, sudah cukup baik, karena luas area Taman mini Indonesia Indah sangat luas dan hampir semua jalanan yang menghubungkan antar objek wisata dengan area parkir sudah diaspal. Hanya ada beberapa objek wisata yang tidak memiliki area cukup lebar untuk pengunjung dengan kursi roda. 
Berdasarkan persyaratan untuk aksesibilitas yang sudah ditetapkan dari UNWTO untuk pergerakan vertikal, belum terpenuhi dengan dengan baik dan menyeluruh. Untuk anjungan daerah semua area belum ada yang dilengkapi dengan lift dan hanya dilengkapi dengan tangga yang terbuat dari kayu atau batu. Demikian juga belum adanya ramp yang tersedia dari jalanan/area parkir ke area dalam objek wisata. Sedangkan yang paling banyak menerapkan lift dan ramp adalah museum, walaupun dengan ruangan lift yang berukuran sempit.

Berdasarkan persyaratan untuk aksesibilitas yang sudah ditetapkan dari UNWTO untuk fasilitas kebersihan umum, Taman Mini Indonesia Indah sudah menyediakan toilet dan tempat mencuci tangan yang banyak tersebar di berbagai tempat dan juga ada yang memang khusus dibangun di dalam area objek wisata. Keadaan ruangan toilet cukup bersih, tetapi yang tersedia sebagian besar masih dalam bentuk toilet jongkok. Belum adanya toilet khusus untuk pengunjung yang menggunakan kursi roda, kecuali ada satu yang terdapat di Bayt Al Quran dan museum Istiqlal. Ini pun belum terdapat tanda bahwa toilet tersebut adalah untuk pengunjung disabilitas.

Berdasarkan persyaratan untuk aksesibilitas yang sudah ditetapkan dari UNWTO untuk harga, sudah diterapkan sangat baik karean untuk semua area Taman Mini Indonesia Indah tidak ada penambahan harga yang dikenakan pada pengunjung berkebutuhan khusus, terutama jika mereka menggunakan fasilitas yang memang disediakan. Seperti penggunaan kursi roda di museum Hakka misalnya, karena kursi roda tersebut memang disediakan khusus untuk pengunjung yang memerlukannya.

\section{SIMPULAN DAN SARAN Simpulan}

Jika dilihat dari tujuh persyaratan yang dikeluarkan oleh UNWTO, Taman Mini Indonesia Indah baru mengimplementasikan sebagian dari tujuh persyaratan yang ada. Yang paling banyak di implementasikan dalam Taman Mini Indonesia Indah adalah komunikasi, signage, dan harga. Sedangkan yang masih memerlukan peningkatan adalah tempat parkir, fasilitas kebersihan umum, pergerakan horizontal dan pergerakan vertikal.
Yang amat sangat perlu untuk diimplementasikan adalah pergerakan vertikal, karena objek wisata yang ada di Taman Mini Indonesia Indah terutama anjungan daerah tidak dapat diakses oleh pengunjung berkebutuhan khusus, terutama jika pengunjung tersebut menggunakan kursi roda. Selain itu yang harus terus ditingkatkan adalah pengimplementasian toilet untuk pengunjung disabilitas.

Objek wisata yang dapat diakses oleh semua orang akan mempunyai keuntungan tersendiri dan menjadi suatu keuntungan dalam persaingan bisnis untuk mendapatkan pengunjung yang banyak.

\section{Saran}

Disarankan agar Taman Mini Indonesia Indah dapat mengeimplementasikan ketujuh persyaratan untuk aksesibilitas yang telah ditetapkan oleh UNWTO. Semakin banyak Taman Mini Indonesia Indah dapat diakses oleh semua orang, semakin banyak pengunjung yang bersedia untuk datang dan berkunjung kembali. Dan Taman Mini Indonesia Indah perlu menyediakan fasilitas yang dapat diakses oleh semua orang dan meningkatkan kualitas dari staf yang bekerja sehingga mereka dapat membantu pengunjung dengan kebutuhan khusus menikmati kunjungan mereka. Dan dapat ditambahkan huruf braille pada brosur untuk pengunjung dengan kekurangan penglihatan. Juga penambahan untuk audio announcement. 


\section{Kepustakaan}

Anugerah, D. K. C. \& Sugandi, M. S., 2018. Strategi Komunikasi Pemasaran Anjungan Taman Mini Indonesia Indah Sebagai Media Promosi Pariwisata Indonesia. Jurnal Ilmu Komunikasi dan Bisnis, 3(2), pp. 82-91.

Benckendorff, . P. J., 2001. Planning for the Future: A Study of Australian Tourist Attractions, Townsville Qld: James Cook University.

Cropley, A., 2019. Qualitative research methods : an introduction for students of psychology and education. 2nd ed. Hamburg: Riga, Latvia : Zinatne.

Devile, E. \& Kastenholz, E., 2018. Accessible tourism experiences: the voice of people with visual disabilities. Journal of Policy Research in Tourism, Leisure and Events, 10(3), pp. 1-21.

ENAT, 2009. What is "Accessible Tourism". [Online] Available at: https://www.accessibletourism.org/resourc es/takayama declaration top-efin 171209.pdf [Accessed 2 October 2019].

IDPWD, 2019. International Day of People with Disabilities. [Online] Available at: https://idpwd.org/ [Accessed 1 August 2019].

Jackson, R., Drummond, D. K. \& Camara, S., 2007. What Is Qualitative Research?. Qualitative Research Reports in Communication, 8(1), pp. 21-28.

Puspasari, N. W. \& . F., 2018. Pengaruh Efektivitas Promosi Above the Line dan Below the Line terhadap Daya Tarik PengunjungTaman Mini Indonesia Indah. Jurnal Riset Manajemen dan Bisnis, 3(3), pp. $313-320$.

Setianda, V. \& Andadari, R. K., 2015.

Menimbang Daya Saing Pariwisata Indonesia (dibandingkan Singapura, Malaysia dan Thailand). Jurnal Manajemen Bisnis Indonesia, 2(3), pp. 422-442.

Silvia , A., 2013. Accessible tourism in the Italian destination. Journal of Tourism Research, Volume 16, pp. 9-29.

Simanjuntak, C., Kusuma Dewi, L. G. L. \& Susrami Dewi, N. G. A., 2018. Penyedia Aksesibilitas bagi Wisatawan Penyandang Disabilitas oleh Stakeholder di Kotamadya Denpasar Kecamatan Denpasar Selatan. Industri Perjalanan Wisata, 6(1), pp. 5569.

Sugianto, S., Sendra, I. M. \& Kusuma Negara, I. M., 2018. Prefensi Wisatawan Cina Terhadap Cultural tourism di Bali.
Industri Perjalanan Wisata, 6(2), pp. 115123.

Thaib, H. S., 2018. Strategi Pengembangan

Kepariwisataan Indonesia, Jakarta: Kementerian Pariwisata.

UNWTO, 2014. Ethics, Culture and Social Responsibility.

[Online]

Available at: http://cf.cdn.unwto.org/sites/all/files/docp df/sanmarinodeclarationonaccessibletouris mfinal1.pdf [Accessed 2 October 2019].

UNWTO, 2016. Accessible Tourism for All: An Opportunity within Our Reach, Madrid: World Tourism Organization .

UNWTO, n.d. Accessible Tourism. [Online] Available at: http://ethics.unwto.org/en/content/accessib le-tourism [Accessed 2 October 2019].

Wardijono, B. et al., 2017. Rancang Bangun Aplikasi Virtual Reality 3D Untuk Menampilkan Visualisasi Lingkungan Taman Mini Indonesia Indah (TMII) Berbasis Web. Jakarta, Universitas Muhammadiyah, pp. 1-7.

Wiastuti, R. D., Adiati , M. P. \& Lestari, N. S., 2018. Implementation of accessible tourism concept at museums in Jakarta. Medan, IOP Publishing Ltd.

World Tourism Organization, 2013. Recommendations on Accesible Tourism, Madrid: UNWTO.

World Travel \& Tourism Council, 2017. How Does Travel \& Tourism Compare to Other Sector?, London: World Travel \& Tourism Council.

World Travel \& Tourism Council, 2019. Destination 2030; Global Cities' Readiness For Tourism Growth, London: JLL \& WTTC.

Zsarnoczky, M., 2017. Accessible tourism in the European Union. Banská Bystrica, ERSA (European Regional Science Association) 